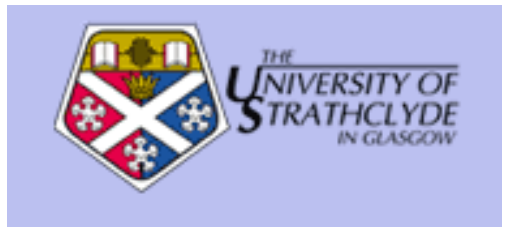

Rosochowski, A. and Olejnik, L. (2009) Ultrafine grains - a new option for light metals. Materials Technology, 24 (3). pp. 139-142. ISSN 1066-7857

http://strathprints.strath.ac.uk/13498/

This is an author produced version of a paper published in Materials Technology, 24 (3). pp. 139-142. ISSN 1066-7857. This version has been peer-reviewed but does not include the final publisher proof corrections, published layout or pagination.

Strathprints is designed to allow users to access the research output of the University of Strathclyde. Copyright (C) and Moral Rights for the papers on this site are retained by the individual authors and/or other copyright owners. You may not engage in further distribution of the material for any profitmaking activities or any commercial gain. You may freely distribute both the url (http://strathprints.strath.ac.uk) and the content of this paper for research or study, educational, or not-for-profit purposes without prior permission or charge. You may freely distribute the url (http://strathprints.strath.ac.uk) of the Strathprints website.

Any correspondence concerning this service should be sent to The Strathprints Administrator: eprints@cis.strath.ac.uk 


\section{Ultrafine grains - a new option for light metals}

Andrzej Rosochowski, Lech Olejnik

\begin{tabular}{|l|}
\hline Andrzej Rosochowski \\
Senior Lecturer \\
Design, Manufacture and Engineering Management \\
75 Montrose Street \\
University of Strathclyde \\
Glasgow G11XJ \\
United Kingdom \\
a.rosochowski@strath.ac.uk \\
\end{tabular}

Lech Olejnik
Senior Lecturer
Institute of Manufacturing Techniques
Warsaw University of Technology
Narbutta 85
02-524 Warsaw
Poland
lolejnik@wip.pw.edu.pl

The potential of ultrafine grained light metals is reviewed. The fundamental metallurgical processes, microstructures developed and properties obtained are first considered. Methods employing severe plastic deformation to achieve ultrafine structures are described and the obstacles to their industrial scale exploitation discussed. Recent advances include the incremental equal channel angular pressing (I-ECAP) process developed at the University of Strathclyde. Ultrafine grained materials are currently utilised in sputtering targets and high value medical devices, but large potential markets exist in the leisure and sports sectors, and in the longer term for aerospace and automotive applications.

Users of metals often treat them as continuous bodies to be formed or machined and often forget that metals are made of grains: discrete domains of different lattice orientation. The polycrystalline nature of metals is too frequently viewed as a 'hidden feature', decided during metallurgical processing and thus remaining beyond the influence of most users converting metals into products. However, this perception may be changed by a new technology, which is much closer to the reach of traditional metals converters. Known as severe plastic deformation (SPD), it is capable of refining the coarse grained (CG) structure of metals and alloys to an average grain size of less than $1 \mu \mathrm{m}$. SPD is a top-down method of producing bulk ultrafine grained (UFG) metals, contrary to the bottom-up methods based on consolidation of nanoparticles. UFG metals possess a range of interesting properties, which make them attractive for advanced applications.

\section{Grain refinement by severe plastic deformation}

The mechanism of grain refinement by SPD is still under investigation. However, the general view is that refinement results from the non-uniform distribution of dislocations, which tend to form cell structures within the original coarse grains. Another opinion emphasises the role of shear bands (thin bands of localised shear deformation) where different bands cross each other to create a pattern resembling a chessboard. The distance between shear bands is very small, which leads to the creation of dislocation cells having sub-micrometre dimensions. The dislocation cells, which do not initially have very different crystallographic orientation from their neighbours, are referred to as subgrains. Only when their misorientation angle exceeds $15^{\circ}$, are they treated as distinct grains. To achieve this state, severe plastic deformation is required. The average grain size of the UFG metals produced depends on the SPD parameters (strain, temperature, pressure) and on the material used; for pure metals, grains tend to be larger, e.g. 0.6 $\mu \mathrm{m}$ for aluminium 1070 (Fig. 1), whereas alloys respond better, e.g. $0.2 \mu \mathrm{m}$ for Al 5083 under similar processing conditions. Sometimes, the average grain size achieved by SPD can reach the nanometre level $(<0.1 \mu \mathrm{m})$ as in the case of nickel subjected to SPD at high pressure. The nanostructuring mechanism described is universal for all metals, but light metals such as aluminium, magnesium and titanium benefit especially from the improvement of properties resulting from grain refinement.

\section{Properties of UFG metals}

Many mechanical and physical properties of metals depend on the grain size. The best known effect is that described by Hall and Petch in the early 1950s, under which the yield stress of polycrystalline materials is inversely proportional to the square root of average grain diameter. This, together with the strain hardening resulting from the increased dislocation density, makes UFG metals much stronger than their CG annealed equivalents. The greatest effect is observed in the case of yield strength, which increases 3-5 times, whereas ultimate tensile strength increases 2-3 times (Fig. 2). Hardness, as a related property, also increases. 

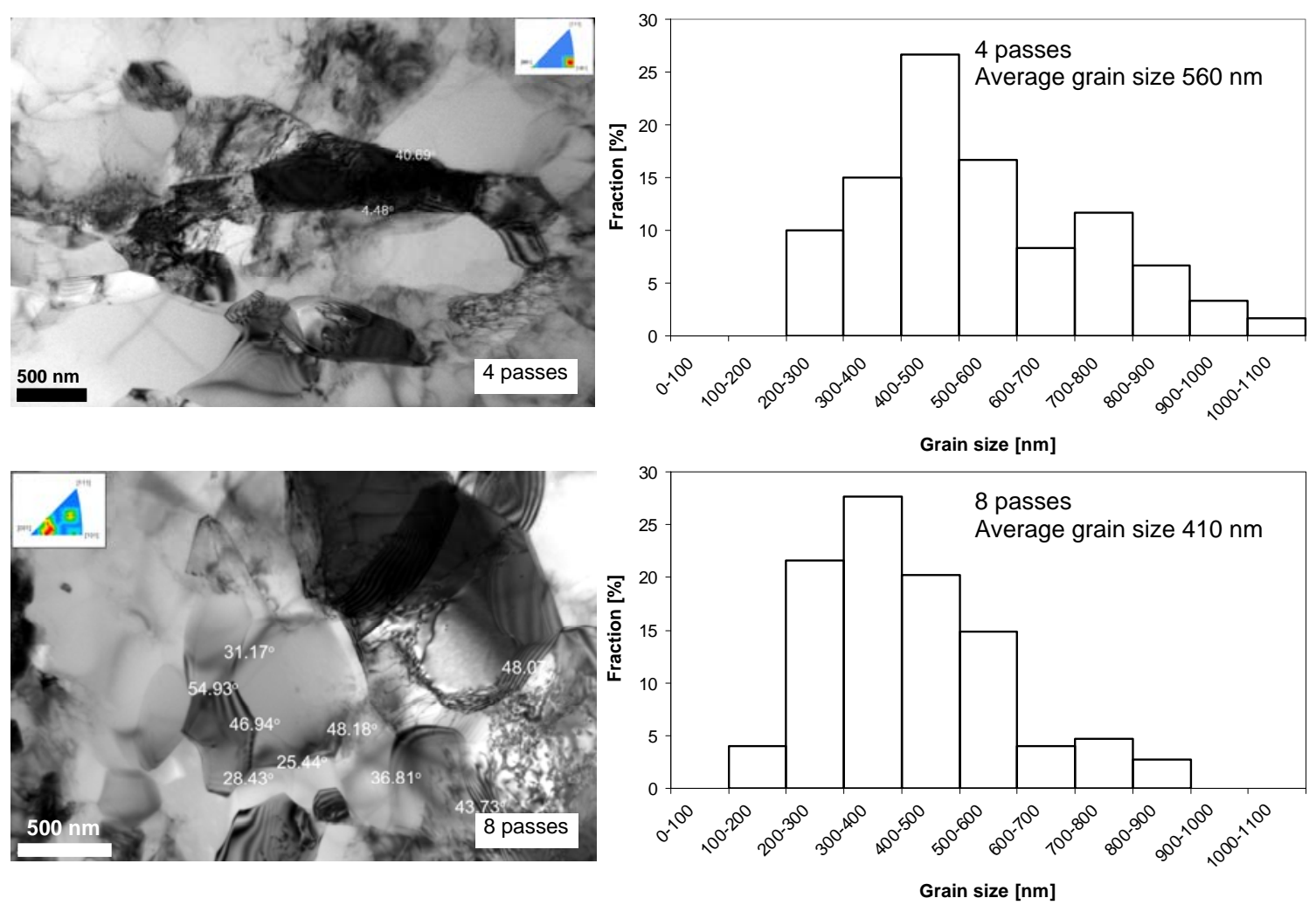

Fig. 1 TEM images and grain size distribution in Al 1070 subjected to 4 and 8 passes of I-ECAP. ${ }^{19}$

In most cases, the increased strength results in proportionally reduced ductility. In some applications this may be acceptable; however, those which require further metal forming to shape material into a component may experience problems. To avoid these problems, machining or metal forming processes that suppress material failure can be used. Interestingly, such metal forming processes are capable of increasing the strength of the UFG metals further, above the level achieved by SPD alone. ${ }^{1}$ Recently, the strength-ductility issue has been re-examined after both increased strength and very high ductility were obtained in pure metals (e.g. in commercial purity (CP) Ti). ${ }^{2}$ There are other examples where ductility has been increased above the normal level. One of these is the case of metals (e.g. CP Ti) deformed at cryogenic temperatures, where the UFG structure leads to improvement of both strength and ductility. ${ }^{3}$ Another example is magnesium alloys, which are very brittle at room temperature but become substantially more ductile in the UFG form. ${ }^{4}$

Fatigue strength/life is another property affected by grain size. In high cycle fatigue, UFG metals produced by SPD exhibit 10-50\% better properties than their CG counterparts. ${ }^{5}$ In contrast, the low cycle fatigue proper-ties of UFG metals are worse than those of CG metals. ${ }^{6}$ This is because material failure is stress related in

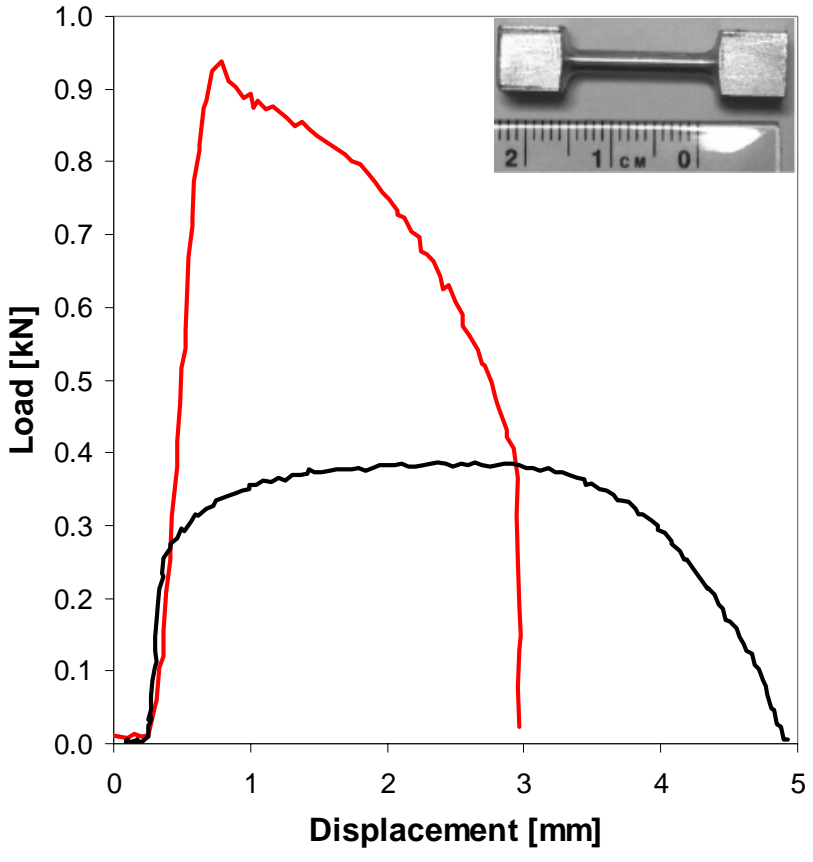

Fig. 2. Tensile behaviour of Al 1070 in initial state and after 8 passes of I-ECAP. ${ }^{19}$ 
high cycle fatigue and plastic strain related in low cycle fatigue. Thus the classical UFG metals with high strength and low ductility perform better when subjected to stress cycling and less well when strain cycled. It would be interesting to investigate whether the strong, ductile UFG metals mentioned above experience an improvement in both high and low cycle fatigue behaviour.

Thermal behaviour of UFG metals is complex. The common wisdom is that, due to the high energy density of the new, 'non-equilibrium' grain boundaries, UFG metals are thermally unstable; thus grain growth should occur at lower temperatures. However, there is experimental evidence, e.g. for $\mathrm{CP} \mathrm{Ti},{ }^{7}$ that this is not necessarily the case. Possibly another mechanism, for example greatly increased grain boundary diffusion, is responsible for rapid recovery of non-equilibrium grain boundaries. High thermal stability can also be achieved by adding precipitate forming elements, e.g. zirconium and/or scandium; ${ }^{8}$ such precipitates reduce the mobility of grain boundaries and suppress grain growth. The enhanced diffusivity mentioned above is responsible for the increased creep rate of UFG metals, ${ }^{9}$ which is not good news for high temperature applications. However, it is beneficial in superplastic forming, promoting the grain boundary sliding thought to be responsible for the extraordinary tensile elongations achieved. ${ }^{10}$

\section{SPD processes}

The amount of plastic strain produced by classical metal forming operations is often limited because of material or tool failure. In some sequential processes, such as rolling or drawing, large reductions of the material thickness can be achieved. However, the billet shapes produced by these processes are unsuitable for further conversion into bulk products. Thus new metal forming processes capable of generating very large plastic deformation without damaging the material and without a major change in billet geometry have been developed. These are based on simple shear and/or repetitive reversed straining, which preserve the initial shape and dimensions of the billet. Despite the lack of shaping capability, SPD processes can be treated as just another branch of the metal forming discipline. The three main SPD processes that have become prominent over the last 30 years are equal channel angular pressing (ECAP), ${ }^{11}$ high pressure torsion (HPT) ${ }^{12}$ and cyclic extrusion compression (CEC) ${ }^{13}$. More recently, new developments, such as multiaxial forging (MF) ${ }^{14}$ repetitive corrugation and straightening (RCS) ${ }^{15}$ and twist extrusion (TE),${ }^{16}$ have been brought forward. New SPD processes are still being developed in an attempt to find the easiest and most efficient solution. Recently, interest has focused on continuous SPD processes, which might be capable of nanostructuring long billets. These include accumulated roll bonding $(\mathrm{ARB})^{17}$ of sheets and various versions of continuously fed ECAP such as, for example, a hybrid of ECAP and the Conform continuous extrusion process (ECAP-Conform) ${ }^{18}$ Another of the new SPD processes is incremental ECAP (I-ECAP), developed at the University of Strathclyde in Glasgow, UK. ${ }^{19}$
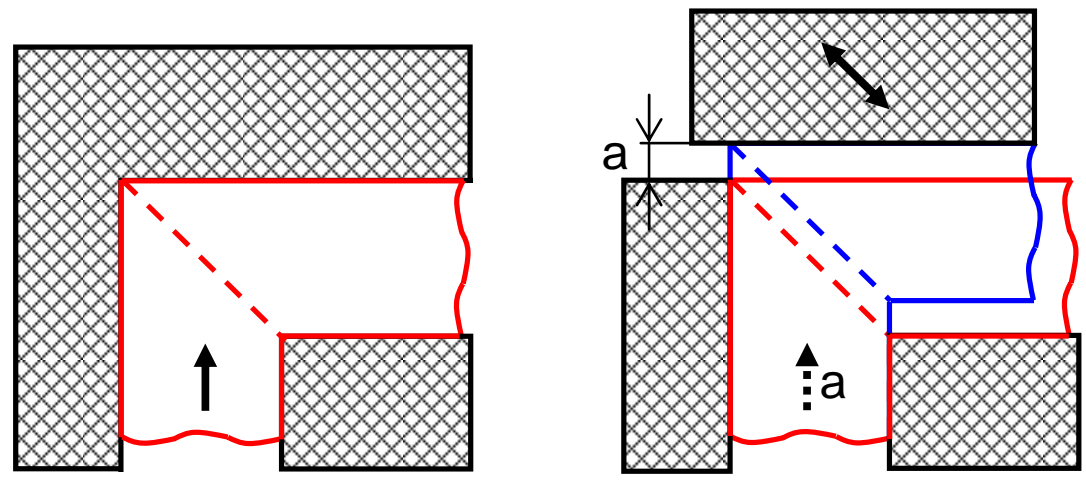

Fig. 3. Schematics of classical ECAP and I-ECAP. ${ }^{19}$
In classical ECAP (Fig. 3), a square or cylindrical billet is pushed from one section of a constant profile channel to another section orientated at an angle $\geq 90^{\circ}$ to the previous one. Plastic deformation of the material is caused by simple shear in a thin layer along the crossing plane of the channel sections. This process is repeated several times with the billet being rotated about its axis between consecutive passes. The length of the leading channel limits the length of the billet processed to about six lateral dimensions; it must not be too long to avoid excessive friction forces and the associated tool design problems. This, together with end effects, causes poor utilisation of the material. Attempts to develop a continuous feeding system have not been entirely successful because the proposed feeding solutions are based on friction which, despite the relatively low force required for ECAP, proves to be problematic. In the I-ECAP process (Fig. 3), the die is split into a fixed part, which leads the billet into the working zone, and a working part, which moves in a reciprocating manner at an appropriate angle to the billet. During feeding of the billet, there is no contact between the billet and the working die. When the billet stops moving and becomes fixed/clamped, the working die deforms it plastically in a localised zone of simple shear. In the next cycle, the feeding and deformation stages are repeated and, provided the feeding stroke is 
not excessive, the consecutive shear zones overlap, giving a uniform strain distribution along the billet. Separation of the feeding and deformation stages reduces or eliminates friction during feeding; this enables processing of effectively infinite billets. I-ECAP can be used for nanostructuring of long bars, plates and sheets, which makes it an attractive option for industrial implementation.

\section{Applications of UFG metals}

Despite a range of improved mechanical and physical properties of bulk UFG metals produced by SPD, the uptake of these materials by industry has been rather slow. One reason for this is the lack of industrial awareness of UFG metals, despite the large number of academics engaged in research on SPD and UFG metals. Another reason is the scarcity of appropriately sized UFG samples for industrial trials; those produced by laboratories are usually too small because they are intended for metallurgical observations or basic mechanical testing. Finally, it is still not clear which of the numerous laboratory based SPD methods will emerge as the most appropriate for industrial implementation. As a result, potential producers of UFG metals hesitate to commit themselves to any particular method. They are also concerned about the commercial viability of UFG metals, which depends on the demand from potential markets and the cost of production. The first commercial applications are likely to be in niche markets producing low volume speciality products (e.g. sputtering targets). These will be followed by medium volume products where the emphasis is on the product's performance rather than price (medical implants, defence applications, aerospace components and sports equipment). Eventually, mass production of components may be undertaken by the automotive and construction industries.

The first commercial application of bulk UFG metals was in sputtering targets for physical vapour deposition. Honeywell offers UFG Al sputtering targets up to $500 \mathrm{~mm}$ in diameter which are produced from plates by an SPD process. ${ }^{20}$ The UFG sputtering targets are used for metallisation of silicone wafers in the production of semiconductor devices. The main two advantages of UFG targets, compared with their CG counterparts, are the $30 \%$ increase in life span owing to the stronger material, which allows use of monolithic targets, and the more uniform coating resulting from reduced arcing.

Applications in the area of medical implants include hip, knee and dental implants as well as various screws, plates and meshes used in orthopaedic applications. Titanium alloys are used for implants because of their low density, high strength, low modulus of elasticity (better matching that of bones), corrosion resistance and good biocompatibility. Commercial purity titanium has better compatibility than titanium alloys, but is not normally strong enough to be used for load bearing implants. However, when nanostructured by SPD and subjected to further thermo-mechanical treatment, cp titanium can achieve a yield stress of $1100 \mathrm{MPa}$, which is comparable with the yield strength of titanium alloys. The first commercial application has been reported by a Czech company, Timplant, which makes UFG titanium dental screws. ${ }^{21}$ The good mechanical properties of the material enable reduction of the screw diameter from 3.5 to $2.4 \mathrm{~mm}$, making it more appropriate for front teeth and dental implants for children. Some studies have shown that in the case of UFG metals the bone integration rate is up to 20 times faster than that for conventional metals; patients should experience shorter post-surgery healing times and more reliable integration of these new implants into their body.

Boeing has started using UFG Ti-6Al-4V sheet produced by VSMPO to improve their superplastic forming (SPF) operations. SPF is a popular technology in the aerospace industry, because it enables complex aircraft panels or engine blades to be manufactured in just one operation. Unfortunately, due to the average grain size of $6-8 \mu \mathrm{m}$ of standard SPF grade Ti-6Al- $-4 \mathrm{~V}$, its $\mathrm{SPF}$ temperature is $900^{\circ} \mathrm{C}$ and the forming time $0.5-1 \mathrm{~h}$. This leads to very short lives of dies, heating elements and press platens, adversely affects surface quality of the SPF components and produces a brittle a-phase case, which has to be etched. The SPF process is characterised by low productivity and high energy consumption, and therefore is expensive. By using a UFG version of Ti-6Al-4V, Boeing has reduced the SPF temperature to $775^{\circ} \mathrm{C}$ and increased the speed of the process, resulting in a dramatic improvement of the process conditions. ${ }^{22}$ Similarly, the diffusion bonding process, which often accompanies SPF, could be improved by reducing its temperature to $775^{\circ} \mathrm{C}$. Interestingly, this temperature is also appropriate for diffusion bonding of UFG Ti-6Al-4V with CG Ti-6Al-4V. ${ }^{23}$

There is an increased interest in metal components in the sub-millimetre range, for which the volume of the material becomes so small that they consist of only a few grains. The departure from the polycrystalline nature of the material causes problems regarding process variability and product quality. To resolve these problems, a much finer grain structure is required. The use of UFG aluminium has proved to be beneficial to the surface quality of microcomponents; $30-50 \%$ reduction of surface roughness can be obtained in micro-forming (Fig. 4), ${ }^{24}$ micro-milling, ${ }^{25}$ 
micro-EDM (electrodischarge machining) and diamond turning of optical surfaces. ${ }^{26}$ Other benefits include increased and more uniform mechanical properties such as yield strength and hardness as well as less variation in the geometrical accuracy of micro-parts.

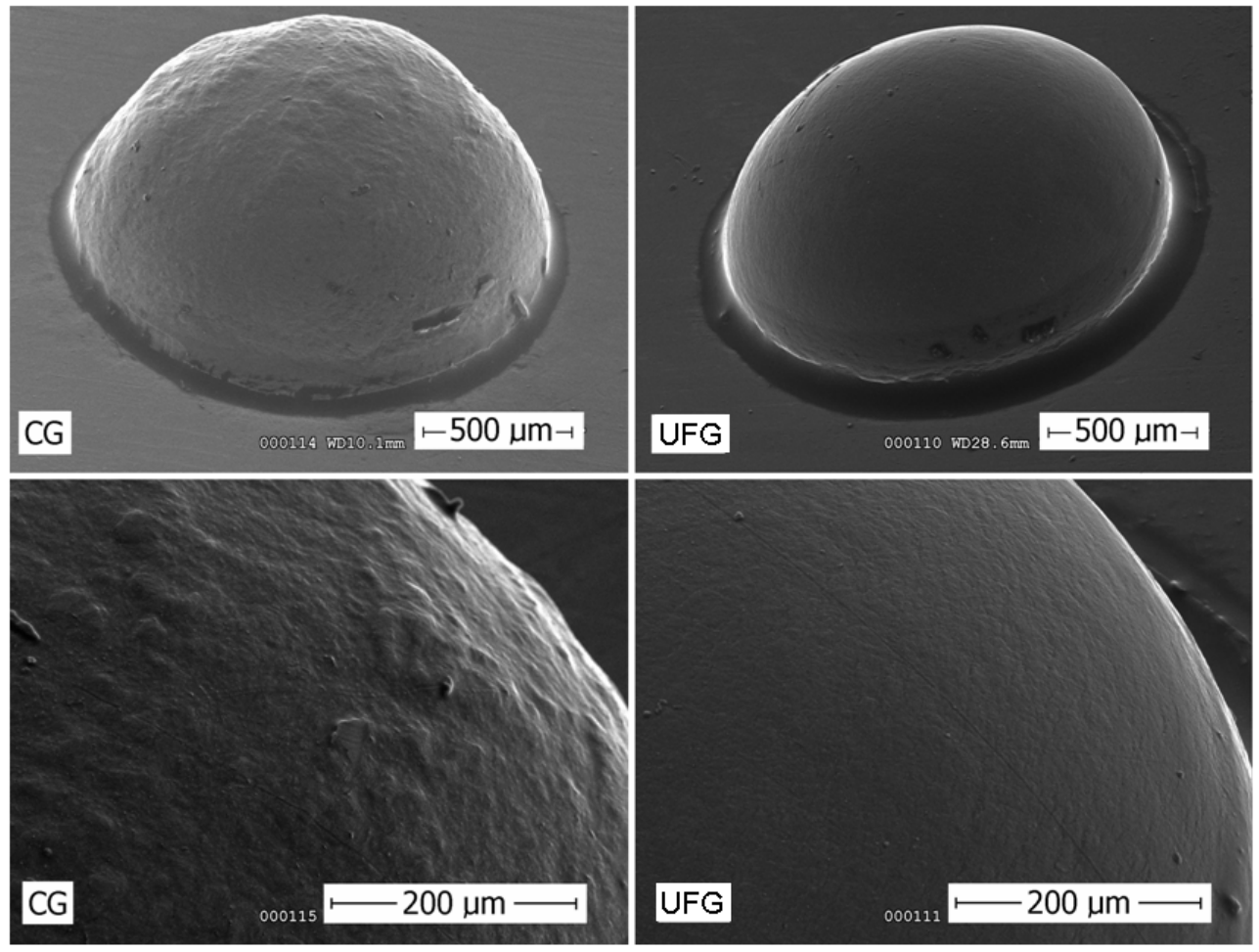

Fig. 4. SEM pictures of the dome part of a microformed component made of CG and UFG Al1070. ${ }^{24}$

A number of laboratory trials of other potential applications have been conducted. A good example of a defence product is a UFG Al 5083 armour plate, which was obtained by cryogenic ball milling (which involves SPD of powder particles), consolidation by hot isostatic pressing, forging or extrusion, and finally rolling. With yield strength of 600-700 MPa and elongation of 11\%, the material exhibited a 33\% improvement in ballistic performance or a similar mass reduction compared with standard armour. ${ }^{27}$ Among the many interesting properties of UFG metals is their ability to flow more easily and at lower temperatures when forged into complex shapes. It is claimed that, for example, energy savings up to $30 \%$ can be achieved when forging UFG Al 6061 due to: lower forging temperature, shorter heating time, smaller forging stock size, fewer forging hits and lower forging load. ${ }^{28}$ Potential applications for UFG metals include high performance bicycles, sailing equipment, mountaineering equipment, and equipment for golf, tennis, hockey and archery. For example, a UFG Ti axle for the bottom bracket of a bicycle was $27 \%$ lighter than the original part made of CG Ti and $62 \%$ lighter than the same part made of a stainless steel. ${ }^{21}$ Since the UFG part was also stronger, its life was substantially extended. An interesting opportunity opens up for UFG magnesium, which is one of the materials being considered for dissolvable cardiovascular stents. ${ }^{29}$ Its improved ductility should assist forming into small tubes and enable the stent mesh to deform.

\section{Summary}

SPD is a top-down method of producing bulk UFG metals. Since the SPD technology is derived from classical metal forming, it has potential to produce UFG metals in quantities and at a cost acceptable to industry. This should open up new markets for the application of UFG metals. The main advantages of UFG products are their improved mechanical properties, which enable lightweight designs and/or lower manufacturing costs. New, sometimes unexpected benefits are likely to be identified by designers of various metallic products as a result of increasing availability of UFG metals and better understanding of their nature. 


\section{References}

1. L. Olejnik, M. Kulczyk, W. Pachla and A. Rosochowski: Proc. 12th Esaform Conf. on Material Forming, Enschede, The Netherlands, April 2009.

2. R. Z. Valiev, A. V. Sergueeva and A. K. Mukherjee: Scr. Mater., 2003, 49, 669-674.

3. Y. Wang, E. Ma, R. Z. Valiev and Y. Zhu: Adv. Mater., 2004, 16, 328-331.

4. T. Mukai, M. Yamanoi, H. Watanabe and K. Higashi: Scr. Mater., 2001, 45, 89-94.

5. I. P. Semenova, G. Kh. Salim gareeva, V. V. Latysh, T. Lowe and R. Z. Valiev: Mater. Sci. Eng. A, 2009, 503, 92-95.

6. H. W. Höppel, M. Kautz, C. Xu, M. Murashkin, T. G. Langdon, R. Z. Valiev and H. Mughrabi: Int. J. Fatigue, 2006, 28, 1001-1010.

7. R. Z. Valiev: in 'Nanomaterials by severe plastic deformation - Nano-SPD2', 109-117; 2002, Weinheim, Wiley$\mathrm{VCH}$.

8. S. Lee, A. Utsunomiya, H. Akama-tsu, K. Neishi, M. Furukawa, Z. Horit a and T. G. Langdon: Acta Mater., 2002, 50, 553-564.

9. V. Sklenicka, J. Dvorak, P. Kral, Z. Stonawska and M. Svoboda: Mater. Sci. Eng. A, 2005, 410-411, 408-412.

10. R. B. Figueiredo, and T. G. Langdon: Adv. Eng. Mater., 2008, 10, 37-40.

11. V. M. Segal: Mat. Sci. Eng. A, 2002, 338, 331-344.1

12. R. Pippan, S. Scheriau, A. Hohen-warter and M. Hafok: Mater. Sci. Forum, 2008, 584-586, $16-21$.

13. M. Richert, H. J. McQueen and J. Richert: Can. Metall. Q., 1998, 37, 449-457.

14. S. V. Zherebtsov, G. A. Salishchev, R. M. Galeyev, O. R. Valiakhmetov, S. Yu. Mironov and S. L. Semiatin:

Scr. Mater., 2004, 51, 1147-1151.

15. J. Y. Huang, Y. T. Zhu, H. Jiang and T. C. Lowe: Acta Mater., 2001, 49, 1497-1505.

16. Y. Beygelzimer, D. Orlov, A. Korshu-nov, S. Synkov, V. Varyukhin, I. Vedernikova, A. Reshetov, A. Synkov, L. Polyakov and I. Korotch-enkova: Solid State Phenom., 2006, 114, 69-78.

17. Y. Saito, N. Tsuji, H. Utsunomiya, T. Sakai and R. G. Hong: Scr. Mater., 1998, 39, 1221-1227.

18. G. J. Raab, R. Z. Valiev, T. C. Lowe and Y. T. Zhu: Mater. Sci. Eng. A, 2004, 382, 30-34.

19. A. Rosochowski, L. Olejnik and M. Richert: Mater. Sci. Forum, 2008, 584-586, 139-144.

20. S. Ferrasse, V. M. Segal, F. Alford, J. Kardokus and S. Strothers: Mater. Sci. Eng. A, 2008, 493, $130-140$.

21. N. A. Reshetnikova, M. R. Salakhova, Z. A. Safargalina and A. V. Scherbakov: Mater. Sci. Forum, 2008, 584$586,9-15$.

22. P. N. Comley: J. Mater. Eng. Perform., 2004, 13, 660-664.

23. L. D. Hefti: Mater. Sci. Forum, 2007, 551-552, 87-93.

24. W. Presz and A. Rosochowski: Proc. 9th Int. Conf. on Material Forming - Esaform2006, Glasgow, UK, April 2006, 587-590; 2006, Krakow, Publishing House Acapit.

25. K. B. Popov, S. S. Dimov, D. T. Pham, R. M. Minev, A. Rosochowski and L. Olejnik: Proc. IMechE B: J. Eng. Manuf., 2006, 220, 1807-1813.

26. J. Osmer, O. Riemer, E. Brinksmei-er, A. Rosochowski, L. Olejnik and M. Richert: Proc. 7th Euspen Int. Conf., Bremen, Germany, May 2007, 316-319.

27. A. P. Newbery, S. R. Nutt and E. J. Lavernia: JOM, 2006, 58, 56-61.

28. R. Srinivasan, B. Cherukuri and P. K. Chaudhury: Mater. Sci. Forum, 2006, 503-504, 371-378.

29. H. Wang, Y. Estrin and Z. Zúberová: Mater. Lett., 2008, 62, 2476-2479. 